\title{
Wave Overtopping Analysis and Early Warning Forecast System
}

\author{
André Sabino $^{1}$, Armanda Rodrigues ${ }^{1}$, João Araújo ${ }^{1}$, Pedro Poseiro ${ }^{2}$, \\ Maria Teresa Reis ${ }^{2}$, and Conceição Juana Fortes ${ }^{2}$ \\ 1 CITI, Departamento de Informática, \\ Faculdade de Ciências e Tecnologia, Universidade Nova de Lisboa, \\ Caparica 2829-516, Portugal \\ amgs@campus.fct.unl.pt, \{a.rodrigues, joao.araujo\}@fct.unl.pt \\ ${ }^{2}$ Hydraulics and Environment Department (DHA), \\ National Laboratory for Civil Engineering (LNEC), \\ Av. do Brasil, 101, Lisbon, 1700-066, Portugal \\ \{pposeiro,treis, jfortes\}@lnec.pt
}

\begin{abstract}
Structures and zones of interest in coastal areas are exposed to wave overtopping events. The consequences associated with those events have a significant impact on human safety, the environment and affected business areas. This paper presents the overtopping forecast, warning and data analysis component of the HIDRALERTA system. The goal of this system is to provide a platform for warning dissemination, while managing the information generated by the risk forecast methodology. Alongside the warning dissemination, the system is concerned with the analysis of previous forecasts and it is designed to account for variability between different zones of interest. Our discussion includes an analysis on the variability expected by the system, a data model for sensor and interpolation data, and the system's user interface, which includes a geo-referenced time-series data analysis tool. We present a case study for Praia da Vitória port, Azores, Portugal.
\end{abstract}

Keywords: Risk Management, Warning System, Geographic Information Systems.

\section{Introduction}

Emergency situations caused by adverse sea conditions incident on maritime structures (breakwaters, groynes, ocean wave/wind energy converts and others) are frequent and endanger the safety of people and goods. They lead to structural damage and wave energy production failure, with negative impacts for the society, the economy and the environment. Therefore, risk management in maritime structures is an important issue and the development of a methodology to warn of emergency situations in port/coastal areas is essential for a proper planning and management of these areas.

This work is focused on forecast and warning of wave overtopping over maritime structures and wave runup on beaches (see definitions in section 2). The 
project has coupled several wave propagation models, which transfer offshore wave conditions to inshore, and then calculates wave overtopping and flooding through artificial neural networks and empirical formulas. Moreover, it compares estimated values of wave overtopping and flood levels with pre-established admissible values in order to define different warning levels. In this paper we describe the warning and data analysis component, which is integrated with the risk assessment component.

The ultimate goal of the project is to build a methodology and system for both long-term planning and forecast and early warning. As a long-term planning tool, the system uses long-term (estimated in years) time series of sea-wave characteristics and/or pre-defined scenarios, and evaluates the sea-wave risks for the protected areas, allowing the construction of GIS based risk maps. These maps aim to support decision-making of the responsible entities regarding long-term management. As a forecast and early warning tool, the system uses numerical forecasts of sea-wave characteristics that allow the identification, in advance, of the occurrence of emergency situations and enables the adoption of measures by those entities, to avoid loss of lives and to minimize damage.

It is also worth noticing that such a tool does contribute to the fulfillment of the stipulated in directive 2007/60/EC of the European Parliament and of the Council of October 23, 2007, which has recommended the development of risk maps by 2013 and flood risk management plans, including the establishment of systems of forecasting and early-warning, by 2015.

The warning system module is already running on a daily basis for Praia da Vitória Port, in Terceira Island (Azores, Portugal) and it is being prepared to run for S. João da Caparica beach, in Costa da Caparica, Portugal.

Alongside the dissemination of warnings, a main goal of the system is the analysis of time series data associated with overtopping events. This enables a better understanding of those events, and the fine tune of risk threshold tables. The information format varies from a single stream of data from one sensor to geo-referenced threat points. One data record from the sensor generates a collection of points with interpolated data.

The contributions of this paper are the following:

- A methodology overview of the HIDRALERTA project, with detailed discussion about the warning system and data analysis component (see section 3);

- A study of the variability involved in overtopping forecast systems for port and coastal areas, summarized in a feature model (see section 3.1);

- A data model to manage sensor and interpolated information (see section 4.1);

- A geo-referenced time series data visualization framework (see section 4.3);

- A case study where the methodology is applied (see section 5).

The next section presents the related work. Section 3 describes the steps of the methodology implemented in the HIDRALERTA system to disseminate warnings and facilitate data analysis. Section 4 describes in detail the warning system. Section 5 describes an example of application of this methodology at Praia da Vitória Port. Finally, in section 6 we discuss future developments for the system. 


\section{Background and Related Work}

This work is focused in building warning systems for two types of events: wave runup and overtopping. Wave runup happens when a wave climbs a beach or structure slope. Overtopping occurs when a volume of water passes over the crest of a structure due to wave action, which may be caused by waves running up the structure slope, exceeding the structure freeboard, and passing a continuous sheet of water over the crest. Overtopping may also happen when a wave hits a vertical structure, sending a vertical plume of water over the crest, or when a wave breaks on the seaward face of the structure and produces splash [1]. The diagrams in figure 1 show the conditions for runup (figure 1a) and for runup and overtopping (figure 1b) events.

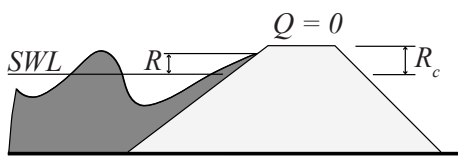

(a) Wave runup

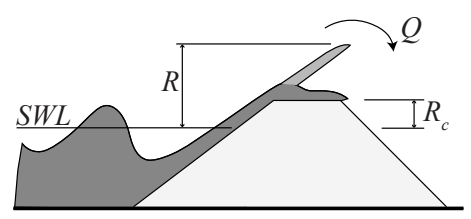

(b) Wave runup and overtopping

Fig. 1. Representation of wave runup, $R$, and overtopping (mean discharge, $Q$ ) events on a structure with freeboard $R_{c}$ (still water level, $S W L$ ).

In countries like Portugal it is extremely relevant to study wave induced risks, and especially wave overtopping, due to the long coastline, the importance of the socioeconomic activities in port/coastal areas and the severity of the sea conditions. In this context, the HIDRALERTA project has been developing a set of integrated decision-support tools for port and coastal management, whose focus is to prevent and support the management of emergency situations and the long-term planning of interventions in the study area.

The stakeholders involved in this type of system are structure owners, civil protection authorities and all other users of the target areas. The warning that is delivered to each type of user differs in the amount of information that characterizes the event. The project is developing a set of warning icons that can be associated with risk levels, which inform the responsible entities about the specific consequences to their interest area.

Unlike other countries (UK and Netherlands) there is not yet in Portugal a flood national forecast and warning system, not even local systems. The experience of the team in developing the GUIOMAR system [2] has been of paramount importance for the successful development of the new more complex system. GUIOMAR is simply a GIS integrated system used for numerical modelling of wave propagation in coastal and port engineering studies.

These systems should enable flood experts to more accurately predict, monitor and warn people about flooding. The development of such a system is the main 
goal of this research project and previous work by the team members in the development of such a system for the North East Region of England [3] has been of great help for the successful achievement of this goal.

The most widely used tools for predicting wave runup and overtopping and the corresponding flooding on beaches, coastal and port structures are still empirical/semi-empirical formulas based on physical model tests or field studies, as shown in [4]. They include the semi-empirical model of Hedges \& Reis [5]. However, the direct application of all these formulae is limited to some wave or water level conditions and simple structural or beach configurations. Physical models remain the most reliable method for determining runup/overtopping. They are used for prototype studies, as well as to provide data for the development, calibration and validation of other prediction methods.

Due to the continuous increase in computer performance, numerical models have been developed further (including by LNEC researchers) and their usefulness is becoming increasingly attractive [6]. They are more flexible than empirical formulas and physical models but their use in practical engineering applications still has limitations [7]. Several artificial neural networks have also been developed lately, including by team members [8] and by the CLASH project team [9].

Team experience in developing Project Life-Saver has been also essential for this work. That project dealt with the evaluation of current emergency measures in the context of the Alqueva dam break $[10,11,12]$. In this context, an emergency scenario simulator was developed and integrated in a decision support system, involving several tools to aid risk management activities for flood emergency scenarios. These results have now been taken a step further, with the aim of automatically providing these tools in different geographic areas and by abstracting the work developed with the creation of generic platform to aid the evaluation of different risk situations in an emergency management context.

\subsection{Software Product Line Engineering}

Variability models are frequently used in the context of Software Product Line Engineering (SPLE) [13]. Our variability model can be used to evolve our framework into an SPL. Producing similar products will take longer than if they belonged to a product line. Hence, many companies decided to use SPLE to develop their products, based in the reuse of components. A SPL is a group of similar software products with commonalities and variabilities, and can be also called product family [13].

SPLE is recommended when you want to produce software in large scale and to satisfy the needs of several clients. Besides, these software products are built using the same platform, which is a set of interfaces and sub-systems which represent a common structure for a group of products [14].

SPLE has two processes, domain engineering and application engineering. In the domain engineering it is defined the platform of a product line and in the application engineering it is configured a specific product [14]. To represent variabilities and commonalities of a product line, we can use feature models. 
A feature model is developed in the domain engineering and configured in the application engineering.

A feature is a property of system relevant to some stakeholders and used to capture common and variable characteristic between products in the same family [15]. Features are organized in a hierarchical diagram like a tree and the root represents a concept (e.g. software system). Each feature can be refined into sub-features. A feature can be classified as mandatory, optional or alternative. In this last case it may be an Or or Xor alternative. We can represent features interaction through a requires link which is used when one feature require another, but the opposite does not occurs [15].

\section{Risk Management Methodology}

The system downloads sea-wave characteristics predicted offshore, up to 180 hours, every day. These data correspond to results obtained through WAVEWATCH III [16], which is a regional model. To transfer the sea-wave characteristics from the WAVEWATCH III to the port entrance and then into the port, SWAN [17] and DREAMS [18] are applied, which are a spectral wave model and a mild slope wave model, respectively. DREAMS model provides wave characteristics in front of each structure, which are then used as input to the neural network tool NN_OVERTOPPING2 [9], together with cross-section characteristics of the maritime structures. NN_OVERTOPPING2 gives an estimate of mean overtopping discharges per unit length of the structure crest [19]. Different thresholds were adopted specifically for each affected structure, bearing in mind the characteristics of the overtopped structure and of the protected area, and the activities developed there. The issue of warnings is activated whenever thresholds are exceeded.

Therefore, the methodology implemented by the HIDRALERTA system integrates four components:

1. Sea-wave characterization, where the sea-wave regime of the zone is obtained from numerical models for sea-wave propagation;

2. Wave overtopping determination, where, based on the characteristics of the zone, a neural network tool predicts wave-overtopping discharges, or empirical formulas are used to evaluate wave runup and overtopping;

3. Risk assessment, which defines a risk level to the predicted overtopping values;

4. Warning system, which integrates all the information and is responsible to disseminate warnings. We present the system in detail in section 4 .

Figure 2 shows how the components integrate with each other.

The sea-wave conditions managed by the system originate from a data source. The data source may represent wave conditions in a single point or in a collection of points. For instance, in our discussion so far, the WAVEWATCH III system is the data source and it provides several data points in a grid. Other data 


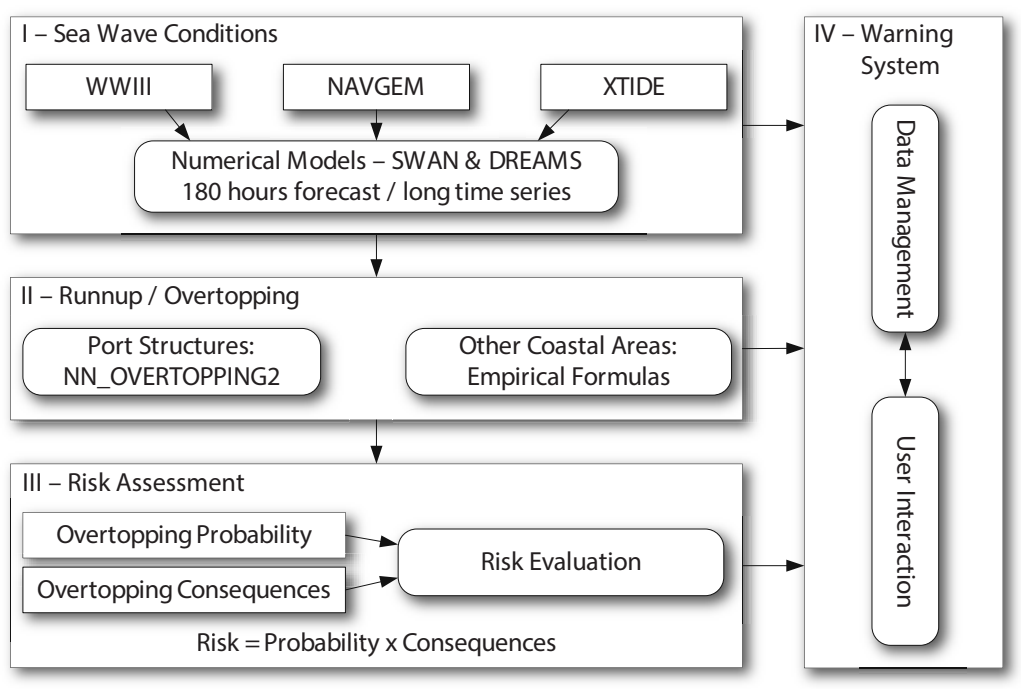

Fig. 2. HIDRALERTA component architecture

sources may be used, like a wave buoy ${ }^{1}$. The data from the data source is then transferred into a finer grid over the study area by the SWAN model. The points in the SWAN grid allow the transfer into an even finer grid by the DREAMS model. Each model operates over a different set of principles. The DREAMS models is tailored for port structures. To support the numerical models used by the system, the data from the WAVEWATCH III are complemented by data from XTide (astronomical tide level) [20] and NAVGEM (wind fields at regional level) [21], as shown in figure 2.

For wave overtopping determination, the methodology accounts for two possible methods, which include the NN_OVERTOPPING2 neural network tool. This tool was developed as part of the CLASH European project [1] and consists on a collection of 700 neural networks trained and tested using a data set obtained from a bootstrapping sampling procedure applied to pairs (input values, mean overtopping discharge) gathered in the same database, which allow the determination of the average value of the mean overtopping discharge and other statistical parameters based on that sample of 700 values. It is tailored for a set of coastal structures, e.g., dikes and rubble-mound breakwaters. To deal with arbitrary coastal areas, HIDRALERTA relies on empirical formulas.

The architecture design in figure 2 was guided by the study of the variability that the system must account to, which we present in section 3.1.

The risk assessment component combines the probability of occurrence of extreme values with the consequences estimated for those same values. The method

\footnotetext{
${ }^{1}$ See http://www. coastwatch.com.au/Weather/WaveHeightBuoys-337/ for examples.
} 
considers a probability scale with different thresholds, and a consequence scale, based on the values generated by

$$
\text { risk = event probability } \times \text { estimated consequences, }
$$

which balances the study of past event (mainly extreme events) with the assessment of the characteristics of the study area. To support these tasks, it is important to provide access to historical data and forecasts. Therefore, we propose a data visualization tool in section 4.3.

The project considers several channels to disseminate warnings (see section 4). The warning message content varies according to dissemination channel used. However, the warning is better understood if represented in a map, where each relevant structure in the region is characterized by the warning level (relevance), the consequences and the sea-wave conditions that lead to the risk level. Section 4 presents the map based representation of a warning.

The expression in equation 1 states that the risk level is the final product of the methodology. Both the probability of events and the consequence scales are defined through a set of procedures detailed in [22]. The risk value is projected into a four value discrete scale that simplifies the warning message. In the risk map associated with a forecast, the risk level is displayed by a color code.

\subsection{Variability}

The HIDRALERTA project is focused on the warning of runup and overtopping events, on specific types of areas, i.e., port and coastal areas. These premises allow for some simplification of the system's design. However, port structures and beach areas are sufficiently different in data acquisition and interpolation to constrain the system's data model.

Spatial data consists obligatorily of cartography, bathimetry and land use. According to the type of coastal area, the DREAMS model may be used. The risk values which are the product of the system may use runup or overtopping tables. Port structures, like the case study presented in section 5, require the use of the DREAMS model to transfer data from the SWAN model, and a final overtopping calculation with the NN_OVERTOPPING2 tools. In a beach scenario, the application of the DREAMS model and the NN_OVERTOPPING2 tool may not be necessary. Empirical formulas are used instead. In both scenarios, more than one WAVEWATCH III data point may be used. Figure 3 shows the feature model of the system, used to represent the expected variability.

For the warning system data model's design presented in section 4.1, the key aspect of the feature model in figure 3 is the several types of data sources, i.e., sensors, according to the study area characteristics.

Table 1 shows the relationships between features and the architecture components on figure 2. The table presents which components of the system are responsible with which requirements, or features. In section 4.1 we present the data model of the warning system (component IV), and discuss the relationships between features and the model's classes. 


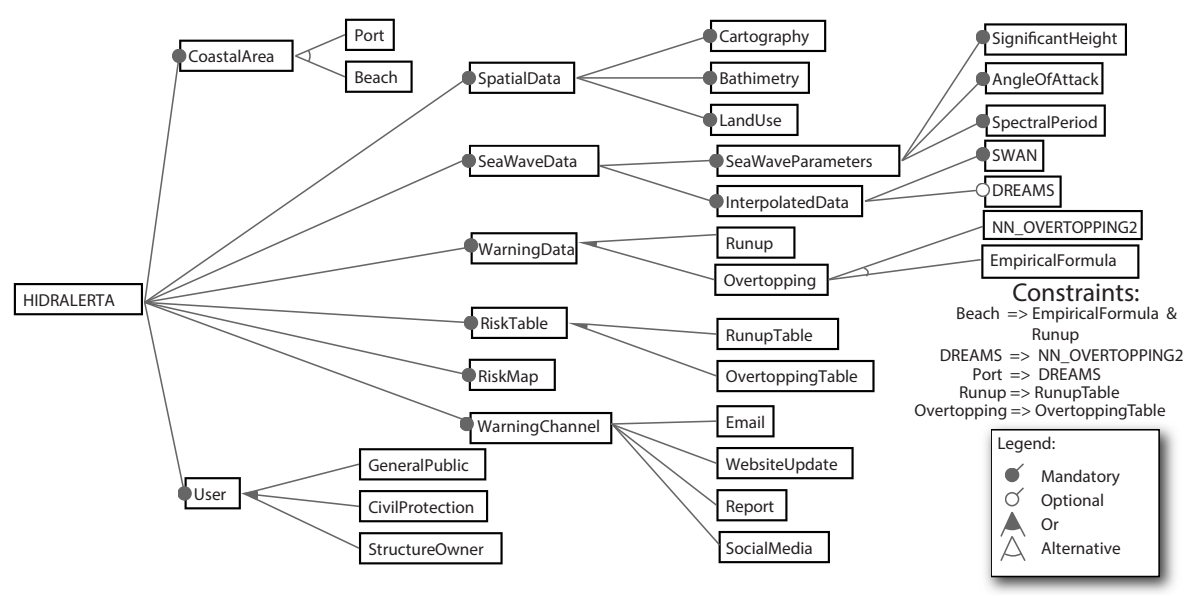

Fig. 3. Feature model for the HIDRALERTA system

Table 1. Relationships between features and components

\begin{tabular}{l|c} 
Feature & Component \\
\hline \hline Coastal Area & I II III IV \\
Spatial Data & I II III IV \\
Sea Wave Data & I II III IV \\
Warning Data & II IV
\end{tabular}

\begin{tabular}{l|c} 
Feature & Component \\
\hline \hline Risk Table & III \\
Risk Map & III IV \\
Warning Channel & IV \\
User & IV
\end{tabular}

\section{Warning System}

The warning system is a component of the methodology described in the previous section (3) and it is designed to assess and disseminate warnings of sea-wave overtopping.

The system integrates all the information that is required from, and generated by, the methodology components. The set of requirements that are component addresses were described by the variability analysis in section 3.1. Specifically, the component deals with the following tasks:

1. Data acquisition from the data sources;

2. Trigger the wave overtopping determination component;

3. Store risk assessment results;

4. Disseminate current warning conditions through the following channels: Website, Twitter account, and Email.

5. Maintain the zone characterization, using a map with the overtopping consequence layer and threat areas;

6. Visualization tools for time series geo-referenced data sources and forecast data. 
The system is managed through a web interface. It manages two types of data: from the data sources and interpolations, and the warning data. The data model in section 4.1 presents the data organization for data sources and interpolation. Its design is constrained by the variability analysis of the system, which is discussed in section 3.1. The warning data follows a straightforward CRUD design approach, supported by the web development framework used (see section 4.4).

\subsection{Data Model}

Section 3.1 presented the feature model of the HIDRALERTA system, while establishing a relationship between each top feature and the components of the system. The main source of variability is the two types of scenarios: generic coastal areas, like beaches; and port areas. Each scenario requires a specific method to determine runup and/or overtopping, from empirical formulas and the NN_OVERTOPPING2 tool accordingly, and require either a runup or overtopping risk table.

Data collected from data sources are managed together with forecast data. Figure 4 illustrates the risk database that integrates information from data sources and the forecasting components, while taking into account the conditions imposed by the feature model, as discussed in section 3.1.

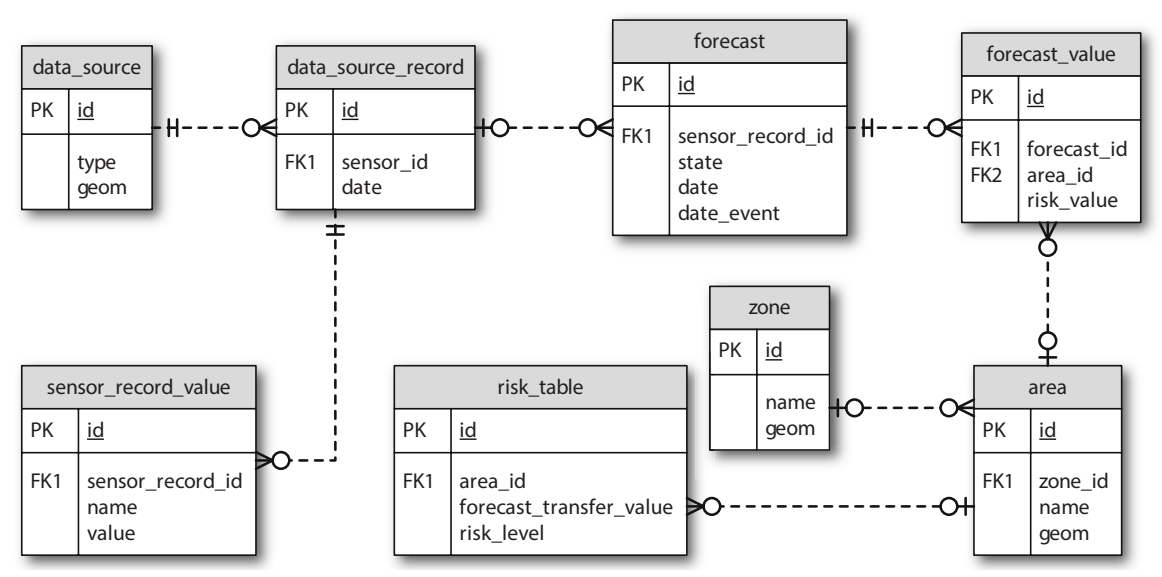

Fig. 4. Data model of the risk database. It manages data from data sources and forecast components.

The terms used in the data model are defined as the following:

Data Source is any source that provides records with the three sea-wave parameters: significant wave height $\left(H_{s}-\mathrm{m}\right)$, spectral peak period $\left(T_{p}-\mathrm{s}\right)$ and angle of wave attack ( $\theta$ - degrees);

Zone is the study area; 
Area is a particular threat area inside the Zone that will be tested for potential overtopping events. Although there is an arbitrary number of areas inside a zone, these are subjected to what is possible to represent on the risk map;

Forecast represents the value of potential overtopping discharges $(\mathrm{l} / \mathrm{s} / \mathrm{m})$, or wave runup $(\mathrm{m})$ for the set of threat areas, with one forecast value for each area;

Risk Table is the threshold table that relates a forecast value with a risk level, for each area. Different areas are subject to different thresholds.

Depending on the zone characteristics, the data source may be a single point location, like a single wave sensor buoy, or a collection of points, like a subset of the WAVEWATCH III grid. The forecast value also varies between a mean overtopping discharge value (NN_OVERTOPPING2) and wave runup information (which is exclusive to the empirical formulas approach). The warning events' data are managed separately by the web application framework, referencing records on the risk database.

Table 2 shows the relationships between the data source and forecast features related with the warning system component and the corresponding tables of the data model.

Table 2. Relationships between data features and data model tables

\begin{tabular}{|c|c|c|}
\hline \multicolumn{2}{|l|}{ Feature } & Data Model Table \\
\hline \multirow{2}{*}{ Sea Wave Data - Interpolated Data } & SWAN & \multirow{2}{*}{ Data Source Record } \\
\hline & DREAMS & \\
\hline \multirow{3}{*}{ Sea Wave Data - Sea Wave Parameters } & Significant Wave Height & \multirow{3}{*}{ Sensor Record Value } \\
\hline & Angle of Wave Attack & \\
\hline & Spectral Peak Period & \\
\hline \multirow{2}{*}{ Warning Data - Runup/Overtopping } & NN_OVERTOPPING2 & \multirow{2}{*}{ Forecast Value } \\
\hline & Empirical Formula & \\
\hline
\end{tabular}

From the model in figure 4, each Forecast requires a specific Data Source Record. This record may refer to any type of sensor that outputs the parameters required by the feature model (as presented in table 2).

\subsection{Time Series Visualization}

The data output from both SWAN and DREAMS models is geo-referenced by points in the models' respective grids. Each point is characterized by the triple $<H_{s}, T_{p}, \theta>$. Furthermore, each threat area is associated with a particular mean overtopping discharge value $(\mathrm{l} / \mathrm{s} / \mathrm{m})$ and the respective risk code. The approach that we suggest is to represent the information for each grid point and threat area, on a risk map. Figure 5 shows the proposal for the risk map, with the grid visualization, the threats, and the values that originated those threats. 


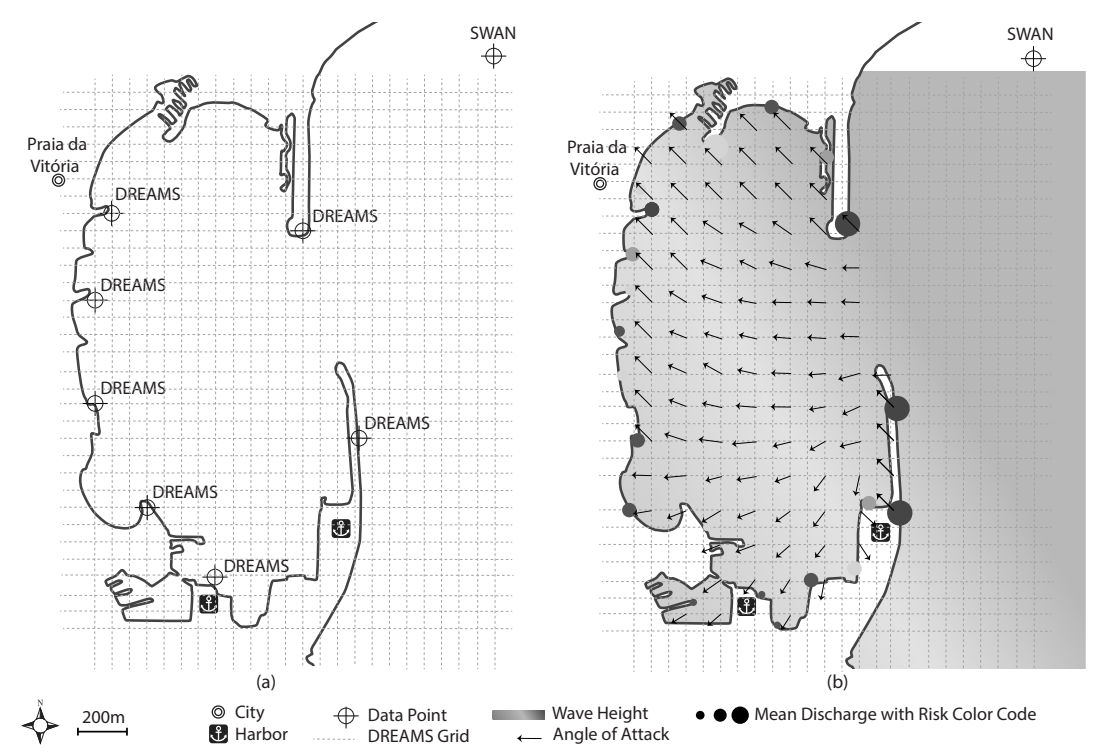

Fig. 5. Map of the Praia da Vitória port with example SWAN and DREAMS data points: a) several points in the DREAMS grid that are candidates for overtopping; b) sea wave conditions on several points of the DREAMS grid inside the port (with wave height and angle of wave attack), and the mean overtopping discharge on several points in the port structures.

The right side of figure 5 shows a single moment in time. Each data record received from the data source will generate one image with the same characteristics. It is then possible to generate an animation with the progression of sea-wave conditions, providing a better context of the forecasts.

This approach is popular among services that deal with GRIB (GRIdded Binary) data, like the WAVEWATCH III (see section 2). Our approach incorporates the data generated by the HIDRALERTA methodology, representing on the same frame values from three data contexts: WAVEWATCH III, SWAN and DREAMS, NN_OVERTOPPING2 or the result from empirical formulas. It also uses the mean discharge value to show the risk code associated with the event. This visualization method is provided by the web interface, presented in the next section.

\subsection{Web Application}

The web application integrates all components of the HIDRALERTA system. It serves as system configuration tool, data management, data analysis and forecast dissemination channel. Figure 6 shows the application architecture. 


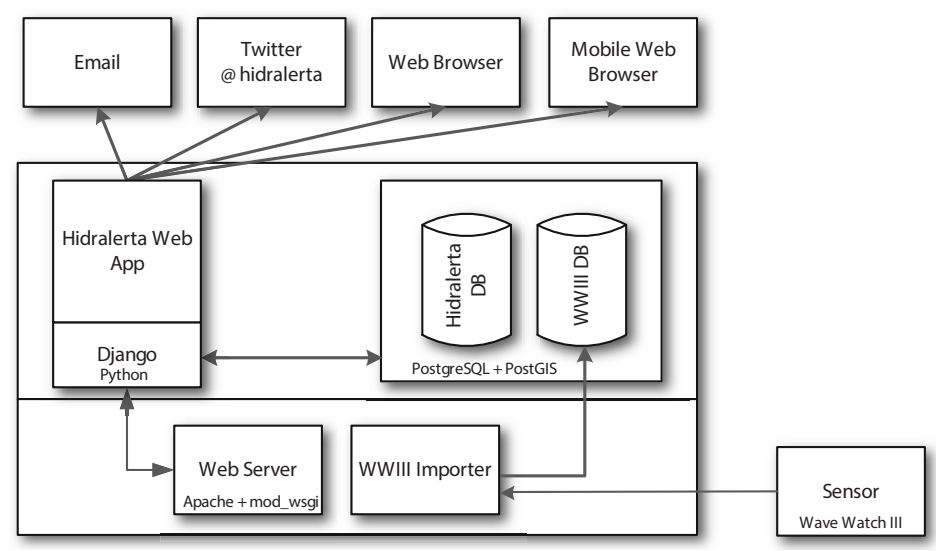

Fig. 6. Web application and interface architecture, with instantiation of sensors and some of the technologies used in the case study (see section 5)

The diagram provides detail into the fourth component of figure 2 , in section 3 - the warning system component. This component manages the collection of sensor data, warning dissemination, and access to historical data.

The web interface was designed to be responsive, expecting clients from both traditional and mobile browsers. Figure 9, in section 5, shows an example of both clients. As mentioned in the beginning of this section, the interface has many purposes, chiefly among them is the detailed description of each early warning. As described in section 3, each warning is characterized by a risk map and a risk code.

\subsection{Techonologies Used}

The web interface is built using the Django ${ }^{2}$ web development framework. The map framework used to build the risk maps is the Google Maps ${ }^{3}$ API. Spatial data management is accomplished through the use of the PostGIS extension of the PostgreSQL ${ }^{4}$ database management system. The chart component is based on HighCharts ${ }^{5}$ javascript library and most of the tools included in the system are developed in Python.

\section{Case Study}

The port and bay of Praia da Vitória are located at the Terceira Island, the second largest of the Azores archipelago. Figure 7 provides an overview of the study

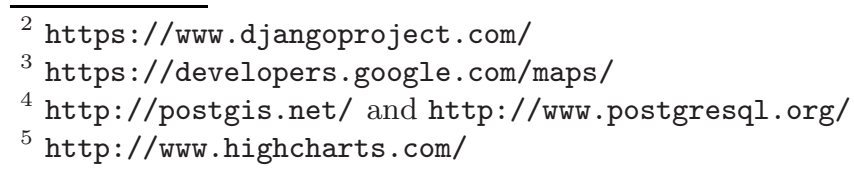




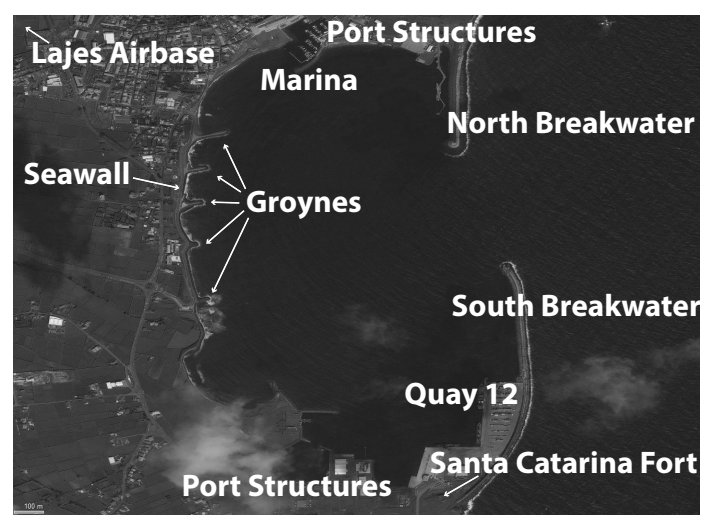

Fig. 7. Main structures and areas of the case study, at Praia da Vitória port, Azores, Portugal.

area. The north breakwater was built to protect the port facilities that support the Lajes airbase. It is a rubble-mound breakwater, $560 \mathrm{~m}$ long, with a northsouth alignment. The second rubble-mound breakwater (the south breakwater) is rooted on the south side of the bay, near the Santa Catarina fort. The breakwater is approximately $1300 \mathrm{~m}$ long, with a straight alignment (north-south) that bends close to its shore connection. It protects the facilities (commercial sector and fishing port) of the Praia da Vitória Port.

The bay shoreline has a coastal road protected by a seawall which is $1 \mathrm{~km}$ long. In front of the port entrance and rooted to the seawall there is a field of five groynes. These groynes do not have the same length but they have approximately the same alignment (WSW-ENE). In the port area, there are now several seawave measuring devices that can characterize the sea-wave regime within the port. In fact, within the scope of the CLIMAAT project [19], a directional wavebuoy was deployed $4 \mathrm{~km}$ northeast from the port, in a region about $100 \mathrm{~m}$ deep, whose data were used to validate the methodology for wave propagation applied in this study.

Currently, the warning system is running permanently for Praia da Vitória. The first module, i.e., sea-wave characterization, runs every day to predict 180 hours of wave propagation at the port entrance and into the port, together with wind field and tide level predictions. For each 3 hours, the system creates a layout for each model with significant wave height $\left(H_{s}\right)$ and angle of wave attack $(\theta)$. It is also possible to create a layout with spectral peak period $\left(T_{p}\right)$.

Once wave characteristics in the port are available, for every 3 hours, the second module is applied, i.e., runup/overtopping. For each set of wave/water level characteristics, NN_OVERTOPPING2 provides information on mean wave overtopping discharges, $Q$, for each of the studied cross-sections of the structures. An example of the layout created by the HIDRALERTA system for NN_OVERTOPPING2 results is presented in figure 8. 


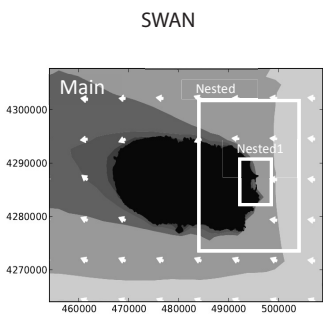

(a)

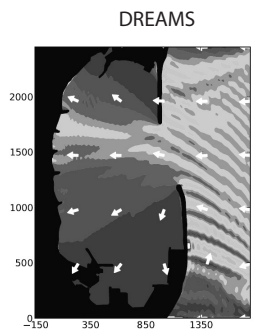

(b)

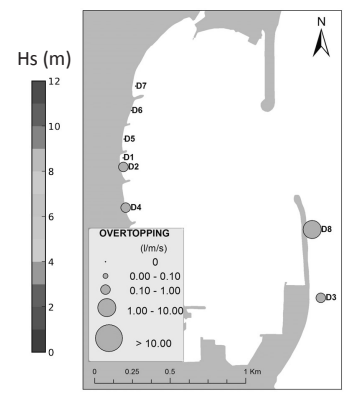

(c)

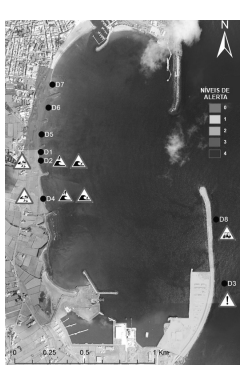

(d)

Fig. 8. Examples of layouts of the HIDRALERTA system in October 16, 2010, 12:00. a) and b) show visualization of the SWAN and the DREAMS results. c) shows mean overtopping discharges at particular locations. d) shows the risk map presented to the responsible authorities, including warning information.

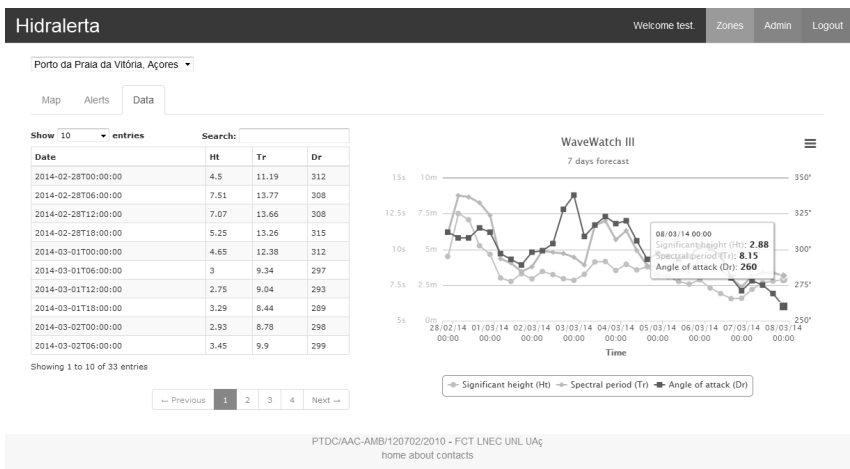

(a)

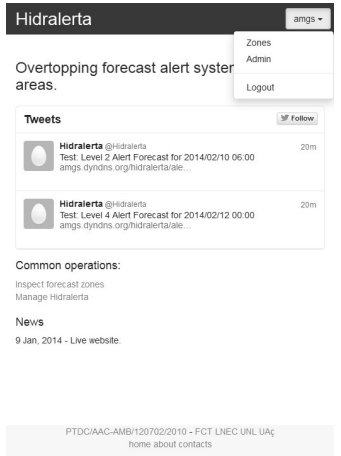

(b)

Fig. 9. HIDRALERTA web interface. a) the real time data analysis page for the desktop version, showing the forecast values for the next 180 hours, provided by WAVEWATCH III. b) the mobile version, showing the twitter feed.

The action signs in the figure $8 \mathrm{~d}$ ) are under development by the projects team and a first version is presented in [22]. The website is not yet released to the responsible authorities. Figure 9 shows its current deploy.

\section{Conclusions and Future Work}

This paper presented the warning and data analysis components of the HIDRALERTA project, whose goal is to develop a system for warning of sea-wave overtopping threats on port and coastal areas. The main contributions are a variability study of the domain, a data model for data source and forecast data 
that enable the analysis of historical and forecast geo-referenced time series. We also propose a visualization strategy that integrates all the information related with a forecast.

The presented variability analysis enabled the definition of the architecture of the system, and the design of the warning system component. In the future we expect to build on the feature model in order to capture more of the variability present in the domain of flood threat on coastal areas.

The system is being developed using the Praia da Vitória port, in Azores, Portugal, as a case study. There are several components under integration. The project plans to conduct several validation steps on the warning system, including the fine tune of warning icons and suitability of the data analysis tools.

Acknowledgements. This work is supported by Fundação para a Ciência e Tecnologia, Ministério da Educação e Ciência, Portugal, through grant PTDC/AACAMB/120702/2010. The authors are grateful for the information on Praia da Viória (port and bay) provided by Portos dos Açores, S.A., Anabela Simões and Eduardo Azevedo from Universidade dos Açores, and Conceição Rodrigues from Azorina Sociedade de Gestão e Conservação da Natureza, S.A.

\section{References}

1. Pullen, T., Allsop, N., Bruce, T., Kortenhaus, A., Schüttrumpf, H., van der Meer, J.: Wave Overtopping of Sea Defences and Related Structures Assessment Manual. Technical report (2007)

2. Neves, D., Zózimo, A., Pinheiro, L., Fortes, C.: GUIOMAR: Geo(graphical) User Interface for cOastal and MARine Modeling. Wave regime at Sines. Journal of Coastal Research SI(56), 1209-1213 (2009)

3. Lane, A., Hu, K., Hedges, T., Reis, M.: New north east of England tidal ood Interface for cOastal and MARine Modeling. Wave regime at Sines. Journal of Practice, 1377-1387 (2008)

4. Raposeiro, P.D., Reis, M., Fortes, C., Ferreira, J.C.: Methodology for estimating run-up and ooding at the costal zone using the GUIOMAR system: application to Vale do Lobo beach. In: Proceedings of the COASTGIS 2009 (2009)0

5. Hedges, T.S., Reis, M.T.: Random wave overtopping of simple seawalls: A new regression model. Water, Maritime \& Energy Journal 130(1), 1-10 (1998)

6. Reis, M., Neves, M., Lopes, M., Hu, K., Silva, L.: Rehabilitation of Sines West Breakwater: wave overtopping study. Proceedings of the ICE - Maritime Engineering 164(MA1), 15-32 (2011)

7. Neves, M.G., Reis, M.T., Losada, I., Hu, K.: Wave overtopping of Póvoa de Varzim breakwater: Physical and numerical simulations. Journal of Waterway,Port, Coastal and Ocean Engineering 134(4), 226-236 (2008)

8. Mase, H., Reis, M., Nagahashi, S., Saitoh, T., Hedges, T.: Effects of zero overtopping data in artificial neural network predictions. In: Proceedings of the Coastal Structures 2007, Venice, Italy, pp. 2-4 (2007)

9. Coeveld, E.M., Van Gent, M.R.A., Pozueta, B.: Neural network manual for NN Overtopping program. Technical report, TU Delft (2005) 
10. Sabino, A., Rodrigues, A.: A visual language for spatially aware agent-based modeling in crisis scenarios. In: Proceedings of the 12th AGILE International Conference on Gepgraphic Information Science (2009)

11. Nóbrega, R., Sabino, A., Rodrigues, A., Correia, N.: Flood Emergency Interaction and Visualization System. In: Proceedings of the 10th International Conference on Visual Information Systems (2008)

12. Sabino, A., Nóbrega, R.: Life-Saver: Flood Emergency Simulator. In: Proceedings of the 5th International ISCRAM Conference (May 2008)

13. Clements, P., Northrop, L.: Software product lines: practices and patterns. Addison-Wesley Longman Publishing Co., Inc. (September 2001)

14. Pohl, K., Böckle, G., van der Linden, F.J.: Software Product Line Engineering: Foundations, Principles and Techniques (September 2005)

15. Kang, K., Cohen, S., Hess, J., Nowak, W., Peterson, S.: Feature-Oriented Domain Analysis (FODA) Feasibility Study. Technical report, CMU, Pittsburgh, PA (1990)

16. Tolman, H.L.: User manual and system documentation of WAVEWATCH III version 2.22. Technical report (2002)

17. Booij, N., Ris, R.C., Holthuijsen, L.H.: A third-generation wave model for coastal regions: 1. Model description and validation (1999)

18. Fortes, C.A.J.: Nonlinear wave transformations in harbors. A finite element analysis. Phd thesis, IST (2002)

19. Neves, D.R., Santos, J.A.A., Reis, M.T., Fortes, C.: Metodologia de avaliação do risco associado ao galgamento de estruturas marítimas. Aplicação ao porto eá baía da Praia da Vitória, Açores, Portugal. Journal of Integrated Costal Zone Management 12(3), 291-312 (2012)

20. Flater, D.: XTide manual: Harmonic Tide Clock and Tide Predictor. Technical report (1998)

21. Whitcomb, T.: Navy Global Forecast System, NAVGEM: Distribution and user support. In: Proceedings of the 2nd Scientific Workshop on ONR DRI: Unified Parameterization for Extended Range Prediction (2012)

22. Poseiro, P., Sabino, A., Fortes, C. A.J., Reis, M.T., Rodrigues, A.: Aplicação do sistema HIDRALERTA de previsão e alerta de inundações: Caso de estudo da Praia da Vitória. In: Proceedings of the 12th Congresso da Água. Number 1 (2014) 